\title{
CLINICO-HAEMATOLOGICAL PROFILE AND AETIOLOGY OF SEVERE ANAEMIA IN TRIBAL CHILDREN - A HOSPITAL-BASED STUDY
}

\author{
Manas Ranjan Behera', Anjana Giri², Shalini Ray 3 \\ ${ }^{1}$ Associate Professor, Department of Paediatrics, Kalinga Institute of Medical Sciences (KIMS), Bhubaneswar, Odisha. \\ ${ }^{2}$ Associate Professor, Department of Pathology, Kalinga Institute of Medical Sciences (KIMS), Bhubaneswar, Odisha. \\ ${ }^{3}$ Assistant Professor, Department of Community Medicine, Kalinga Institute of Medical Sciences (KIMS), Bhubaneswar, Odisha.
}

\section{ABSTRACT}

\section{BACKGROUND}

Anaemia is a significant public health problem in India. Iron and other nutritional deficiencies including vitamin B12, folate and vitamin $\mathrm{A}$, acute and chronic inflammation, inherited or acquired haemoglobin disorders can cause anaemia. Severe anaemia is a major cause of hospitalisation in tribal children in this part of country.

\section{MATERIALS AND METHODS}

All the children admitted to the hospital in last three years with the diagnosis of severe anaemia, fulfilling the inclusion criteria were included in this retrospective study. Case records were analysed to obtain data on clinical signs and symptoms, haematological and biochemical parameters, treatment received and outcome. Descriptive analysis was done.

\section{RESULTS}

Out of 136 tribal children with severe anaemia, $66.9 \%$ were girls and $33.1 \%$ were boys. The mean age of the study participants was $11.2 \pm 2.2$ years with a range of $2-15$ years; $73.5 \%$ of the children were in the age group of $11-15$ years. Generalised weakness and pallor were the most common presenting symptoms, whereas pallor and hepatomegaly were the most common signs on clinical examination. Microcytic hypochromic and macrocytic anaemia were seen in $25 \%$ and $11.8 \%$ cases respectively. Only $5 \%$ children had exclusively iron deficiency anaemia and the rest 95\% had mixed aetiology. Vitamin B12 and folic acid levels were found to be low in $68.4 \%$ and $36.8 \%$ cases respectively; $27.2 \%$ were found to be deficient in both; $20.5 \%$ children had acute or chronic inflammation. Haemoglobinopathies were seen in 9.6\% and glucose-6-phosphate dehydrogenase (G6PD) deficiency was seen in $5.5 \%$ cases.

\section{CONCLUSION}

Several independent and overlapping conditions are associated with severe anaemia in tribal children and a definitive diagnosis must be made for correct therapeutic intervention.

\section{KEYWORDS}

Anaemia, Severe Anaemia, Tribal Children, Aetiology.

HOW TO CITE THIS ARTICLE: Behera MR, Giri A, Ray S. Clinico-haematological profile and aetiology of severe anaemia in tribal children - a hospital-based study. J. Evolution Med. Dent. Sci. 2016;5(88):6536-6540, DOI: 10.14260/jemds/2016/1479

\section{BACKGROUND}

Anaemia is a condition in which the number of red blood cells and consequently their oxygen-carrying capacity is insufficient to meet the body's physiological needs. ${ }^{1}$ It is a global problem, mainly affecting poor people in developing countries with major consequences for human health as well as social and economic development. ${ }^{2}$ Thirty five percent of women and $43 \%$ of young children are affected by anaemia worldwide. ${ }^{3}$ In developing countries $50 \%$ of women and young children are anaemic. ${ }^{3}$

Iron deficiency is thought to be the most common cause of anaemia globally, but other nutritional deficiencies (Folate, vitamin B12 and vitamin A), acute and chronic inflammation, parasitic infections and inherited or acquired disorders that affect haemoglobin synthesis, red blood cell production or survival can cause anaemia. ${ }^{1}$ Anaemic children continue to

Financial or Other, Competing Interest: None.

Submission 12-10-2016, Peer Review 25-10-2016,

Acceptance 27-10-2016, Published 02-11-2016.

Corresponding Author:

Dr. Manas Ranjan Behera,

Qr. No. D/15, Staff Qr.,

KIMS Campus, KIIT University, Patia,

Bhubaneswar-751024, Odisha.

E-mail:drmanas73@yahoo.co.in

DOI: $10.14260 /$ jemds $/ 2016 / 1479$ have poor cognition and school achievement, poor growth and more behaviour problems. ${ }^{4}$ Severe anaemia is an important cause of maternal and childhood mortality. In Sub-Saharan Africa 12 to $29 \%$ of hospitalised children are severely anaemic and the in-hospital case fatality rate in these children is 8 to $17 \% .^{5}$ Little is known about the incidence and causes of severe anaemia in Indian children.

Odisha is the second largest tribal dominant state in the country constituting $22.3 \%$ of the total population. 6 There is a heavy burden of communicable, non-communicable and silent killer genetic diseases prevalent in tribal communities of Odisha. ${ }^{7}$ Our institute caters to around 15000 tribal children, who study in tribal schools nearby. All belong to scheduled caste and scheduled tribes from different parts of Odisha. We observed a high rate of hospitalisation of tribal children for severe anaemia in our institution. Hence, the study was undertaken. The objective was to identify the aetiology and to assess the clinical and haematological profile of severe anaemia in tribal children admitted to the hospital.

\section{MATERIALS AND METHODS}

This was a retrospective record based study conducted at a tertiary care teaching hospital of Odisha. The data from September 2013 to August 2016 were analysed in a period of one month. All the case records of children in the age group of 1 to 15 years admitted to the hospital with diagnosis of 
'anaemia' or 'severe anaemia' were retrieved from the medical records department.

The inclusion criteria for the study were tribal children, aged 1 to 15 years having severe anaemia. Tribal children were identified from the case records. Children with prior history of blood transfusion or any surgical procedure in last 3 months with active bleeding or any bleeding disorder, known cases of sickle cell anaemia or thalassemia and children with malignancy were excluded from the study. All the records thus obtained were thoroughly analysed and information on demographic profile, clinical features, laboratory investigations, complications and treatment were recorded in a predesigned proforma.

Severe anaemia was defined as haemoglobin levels less than 7 gram per decilitre in children aged 6 to 59 months and less than 8 gram per decilitre in the age group of 5 to 14 years and above as per WHO. ${ }^{1}$ Iron deficiency anaemia was diagnosed by the presence of microcytosis (Mean corpuscular volume less than the cut-off value for age and sex) or hypochromasia (Mean corpuscular haemoglobin concentration less than 32 gram per litre) in the absence of thalassemia trait or sideroblastic anaemia. ${ }^{8}$ In the presence of infection or inflammation Iron Deficiency Anaemia (IDA) was diagnosed if serum transferrin saturation was less than $16 \% .{ }^{9}$ Vitamin B12 and folic acid deficiencies were identified if the serum values were less than the cut-off value for age and sex.10 Complete Blood Count (CBC) including reticulocyte count was done by automated haematology analyser (Beckman coulter LH 750 and Sysmex 1000i). Serum iron, ferritin, Total Iron Binding Capacity (TIBC) and transferrin saturation values were estimated using Cobas Integra 400 machine by Ferrozine method. Serum vitamin B12 and folic acid levels were estimated on Cobas e411 machine by ECLIA method. Peripheral smears were done using Leishman's stain. Haemoglobinopathies were confirmed by High Performance Liquid Chromatography (HPLC).

Statistical analysis was done using Epi-Info 2000. Univariate and bivariate frequency tables were generated based on categorical data. Association between parameters was studied using chi-square test at appropriate level of significance. Association was considered to be statistically significant at $P$ value $<0.05$.

\section{RESULTS}

A total of 188 cases with clinical diagnosis of 'anaemia' or 'severe anaemia' were admitted during the study period. Fifty two cases were excluded as per the criteria (Known case of sickle cell anaemia or thalassaemia in 24 cases, acute leukaemia in 8 cases, bleeding disorders in 4 cases, severe falciparum malaria in 7 cases and 9 non-tribal children with anaemia). So for the final analysis, 136 case records were considered.

The age and sex distribution of 136 tribal children who were admitted for severe anaemia is shown in Table 1 . The mean age of the study participants was $11.2 \pm 2.2$ years with a range of $2-15$ years; $73.5 \%$ of the children were in the age group of 11-15 years. Severe anaemia was found to be more common in girls $(66.9 \%)$ as compared to boys (33.1\%). The presenting complaints and clinical signs on admission are depicted in Table 2 and Table 3 respectively.
Generalised weakness and pallor were the most common presenting symptoms, whereas pallor and hepatomegaly were the most common signs on clinical examination. Mean duration of hospital stay was $8.11 \pm 3.7$ days.

The haematological parameters are shown in Table 4. Mean Corpuscular Volume (MCV) was found to be normal in 86 (63.2\%), low in 34 (25\%) and high in 16 (11.8\%) children with severe anaemia. Accordingly, the types of anaemia with frequency are illustrated in Table 5. Mean Corpuscular Haemoglobin Concentration (MCHC) is found to be low in 127 (93.4\%) children. Both MCV and MCHC were low in 34 (25\%) children. Reticulocyte count was found to be high in 12 (8.8\%) children suggestive of haemolysis. Thrombocytopenia was found in $43(31.6 \%)$ children, whereas pancytopenia was seen in $28(20.5 \%)$.

Out of 28 cases of pancytopenia, 13 (46.4\%) had vitamin B12 deficiency, 11 (39.3\%) had both vitamin B12 and folate deficiency, $3(10.7 \%)$ had folate deficiency only and one (3.6\%) had hypersplenism. Bone marrow biopsy was done in 15. All had megaloblastic changes suggestive of severe vitamin B12 deficiency.

Vitamin B12 and folic acid levels were found to be low in $93(68.4 \%)$ and $50(36.8 \%)$ cases respectively. Thirty seven children $(27.2 \%)$ were found to be deficient in both; $72.9 \%$ of children in the age group 11-15 years were having vitamin B12 deficiency. Twenty four children (25.8\%) with low vitamin B12 levels had pancytopenia.

Serum ferritin levels were found to be low in only 5 (3.7\%) children. High values were seen in 38 (28\%) and normal in 93 (68.3\%) children. Serum iron levels were done in 122 cases. It was found to be low in 25 (20.5\%) and high in $28(23 \%)$ children. Transferrin saturation was found to be low $(<16 \%)$ in 23 (17\%) children.

Glucose 6 phosphatase (G6PD) estimation was done in 72 children and out of them $4(5.5 \%)$ were found to be deficient. Liver function tests were done in 79 children. Indirect hyperbilirubinaemia was found in 27 (34.2\%); raised AST and ALT levels were seen in 23 (29.1\%) and 7 (8.9\%) children respectively. Haemoglobinopathies were detected in 13 (9.6\%) children (Table 7).

Out of 26 febrile children who were investigated for infection 6 had plasmodium vivax, 4 had plasmodium falciparum and another 4 had mixed infection. Eleven children were diagnosed having pneumonia and 5 had culture proven urinary tract infection. Two children were found to have pulmonary tuberculosis.

Seventy eight (57.4\%) children received packed red blood cell transfusion. All the cases were managed appropriately according to the cause with antibiotics, parenteral cobalamin, oral folic acid and oral iron in therapeutic doses. There was no mortality in the study population.

\begin{tabular}{|c|c|c|c|}
\hline $\begin{array}{c}\text { Age } \\
\text { (Yrs.) }\end{array}$ & $\begin{array}{c}\text { Male } \\
(\mathbf{n = 4 5})\end{array}$ & $\begin{array}{c}\text { Female } \\
(\mathbf{n = 9 1})\end{array}$ & Total \\
\hline $1-5$ & $2(100 \%)$ & 0 & $2(1.5 \%)$ \\
\hline $6-10$ & $9(26.5 \%)$ & $25(73.5 \%)$ & $34(25 \%)$ \\
\hline $11-15$ & $34(34 \%)$ & $66(66 \%)$ & $100(73.5 \%)$ \\
\hline \multicolumn{4}{|c|}{ Table 1. Age and Sex Distribution } \\
of Children with Severe Anaemia
\end{tabular}




\begin{tabular}{|c|c|c|}
\hline Symptoms & No. of Patients & $\%$ \\
\hline Generalised Weakness & 124 & 91.2 \\
\hline Pallor & 112 & 82.3 \\
\hline Loss of Appetite & 92 & 67.6 \\
\hline Joint Pain/Myalgia & 88 & 64.7 \\
\hline Reeling of Head & 69 & 50.7 \\
\hline Headache & 58 & 42.6 \\
\hline Facial Puffiness & 42 & 30.9 \\
\hline Oedema Feet & 29 & 21.3 \\
\hline $\begin{array}{c}\text { Generalised } \\
\text { Swelling Body }\end{array}$ & 28 & 20.6 \\
\hline Cough & 28 & 20.6 \\
\hline Fever & 26 & 19.1 \\
\hline Syncope & 12 & 8.8 \\
\hline Icterus & 12 & 8.8 \\
\hline PICA & 2 & 1.5 \\
\hline \multicolumn{3}{|c|}{ Table 2. Symptomatology of Severe Anaemia } \\
\hline
\end{tabular}

\begin{tabular}{|c|c|c|}
\hline Type of Anaemia & Number & Percent \\
\hline Microcytic Hypochromic & 19 & 14 \\
\hline Dimorphic & 93 & 68.4 \\
\hline Macrocytic & 2 & 1.5 \\
\hline Pancytopenia & 18 & 13.1 \\
\hline Haemolytic & 4 & 3 \\
\hline
\end{tabular}

\begin{tabular}{|c|c|}
\hline Genetic Disorders & Number (17) \\
\hline $\begin{array}{c}\text { Double Heterozygous for } \\
\text { HBS \& Beta Thalassaemia }\end{array}$ & 2 \\
\hline $\begin{array}{c}\text { Double Heterozygous for HBS } \\
\text { \& Beta Thalassaemia +B12 DEFF. }\end{array}$ & 1 \\
\hline $\begin{array}{c}\text { Double Heterozygous for HBS \& } \\
\text { Beta Thalassaemia +B12 DEFF + FA DEFF. }\end{array}$ & 1 \\
\hline Sickle Cell Disease (SCD) & 1 \\
\hline SCD + IDA & 2 \\
\hline SCD + B12 DEFF. & 2 \\
\hline Sickle Cell Trait + IDA & 1 \\
\hline Thalassaemia Trait+ & 2 \\
\hline B12 DEFF + FA DEFF. & 1 \\
\hline Thalassaemia Trait + IDA & 2 \\
\hline $\begin{array}{c}\text { G6PD DEFF. + B12 } \\
\text { DEFF. + FA DEFF. }\end{array}$ & 2 \\
\hline G6PD DEFF. + IDA \\
\hline $\begin{array}{c}\text { Table 7. Genetic Disorders } \\
\text { Associated with Severe Anaemia }\end{array}$ \\
\hline
\end{tabular}

\begin{tabular}{|c|c|c|}
\hline Clinical Signs & No. of Patients & Percentage \\
\hline Pallor & 136 & 100 \\
\hline Hepatomegaly & 72 & 52.9 \\
\hline Facial Puffiness & 54 & 39.7 \\
\hline Splenomegaly & 45 & 33 \\
\hline Pedal Oedema & 42 & 30.9 \\
\hline $\begin{array}{c}\text { Conjunctival } \\
\text { Xerosis }\end{array}$ & 35 & 25.7 \\
\hline Icterus & 32 & 23.5 \\
\hline $\begin{array}{c}\text { Knuckle } \\
\text { Hyperpigmentation }\end{array}$ & 31 & 22.8 \\
\hline Fever & 28 & 20.5 \\
\hline $\begin{array}{c}\text { Signs of Congestive } \\
\text { Heart Failure }\end{array}$ & 5 & 3.7 \\
\hline Lymphadenopathy & 5 & 3.7 \\
\hline Ascitis & 4 & 2.9 \\
\hline \multicolumn{3}{|c|}{ Table 3. Clinical Signs of Severe Anaemia } \\
\hline
\end{tabular}

\begin{tabular}{|c|c|}
\hline Haematological Parameters & Values \\
\hline Haemoglobin (Gram/dL) & $5.2 \pm 1.5$ \\
\hline Total RBC Count (106/microlit) & $2.1 \pm 0.8$ \\
\hline Packed Cell Volume (\%) & $17.4 \pm 4.9$ \\
\hline MCV (fl) & $84.3 \pm 13.6$ \\
\hline MCH (pg) & $25.5 \pm 4.9$ \\
\hline MCHC (\%) & $30.1 \pm 1.6$ \\
\hline RDW (\%) & $30.8 \pm 6.5$ \\
\hline Total Platelet Count & $205.6 \pm 121.5$ \\
\hline Table 4. Haematological Profile of Children \\
with Severe Anaemia \\
\hline
\end{tabular}

HBS: Sickle Haemoglobin, SCD: Sickle Cell Disease, IDA: Iron Deficiency Anaemia, FA: Folic Acid, G6PD: Glucose 6 Phosphate Dehydrogenase.

\begin{tabular}{|c|c|}
\hline Aetiology & Number (\%) \\
\hline IDA + VIT B12 DEFF & $26(19.1 \%)$ \\
\hline IDA + B12 DEFF + FA DEFF & $19(14 \%)$ \\
\hline IDA + B12 DEFF & $19(14 \%)$ \\
\hline B12 DEFF + FA DEFF & $12(8.8 \%)$ \\
\hline IDA + CHR INF & $10(7.3 \%)$ \\
\hline Iron DEFF Anaemia & $7(5.1 \%)$ \\
\hline IDA + FA DEFF & $7(5.1 \%)$ \\
\hline IDA + B12 DEFF + CHR INF & $7(5.1 \%)$ \\
\hline B12 DEFF + CHR INF & $5(3.7 \%)$ \\
\hline B12 DEFF + FA DEFF + CHR INF & $5(3.7 \%)$ \\
\hline IDA + FA DEF + CHR INF & $2(1.5 \%)$ \\
\hline Table 8. Aetiology of Severe Anaemia \\
\hline \multicolumn{2}{|c}{} \\
\hline
\end{tabular}

\section{DISCUSSION}

Tribal children from Odisha suffer disproportionately from malaria, tuberculosis, genetic disorders like G6PD deficiency, sickle cell anaemia, malnutrition and nutritional deficiency diseases. ${ }^{6}$ Severe anaemia in tribal children is one of the leading causes of hospitalisation in our institute and the aetiology has not been thoroughly investigated.

In the present study, girls were found to be more commonly affected with severe anaemia than boys (91:45). Maximum number of cases was adolescents in the age group of 11 to 15 years. Similar observations were made by other studies. ${ }^{11}$ Adolescents are vulnerable to iron deficiency because of increased iron requirements related to rapid growth. 
Iron needs are highest in males during peak pubertal development because of greater increase in blood volume, muscle mass and myoglobin. ${ }^{12,13}$ After menarche, iron needs continue to remain high in females because of menstrual blood loss. ${ }^{14}$

Red blood cell hypochromasia was seen in $93.4 \%$ cases, whereas both microcytosis and hypochromasia were seen in only $25 \%$ suggestive of iron deficiency. But when serum transferrin saturation value was taken into consideration for diagnosis of Iron Deficiency Anaemia (IDA), the incidence further decreased to $17 \%$. Serum ferritin values were low in only $3.7 \%$ children. The normal serum transferrin saturation and ferritin in other children could be due to associated infection, chronic disease, chronic inflammation, liver disease or haemolysis due to some known or unknown factors.

In the present study, we found high serum ferritin levels in $38(28 \%)$ children. As serum ferritin is a marker of acute or chronic inflammation, this high level could be due to presence of acute infection or chronic disease. Similar studies have shown chronic inflammation to be one of the common causes of anaemia in infants and children. ${ }^{15,16}$ Raised serum ferritin levels are also seen in haemolytic anaemia, haemochromatosis and sideroblastic anaemia. Twenty eight children had some kind of bacterial or parasitic infections (Urinary tract infection, pneumonia, scabies, malaria, tuberculosis). Low vitamin B12 levels can predispose the red blood cells for haemolysis. ${ }^{17}$ Out of these 38 children, serum vitamin B12 levels were found to be low in 28 (73.7\%). Eighteen (47.3\%) children had feature of haemolysis in peripheral smear.

Vitamin B12 levels were found to be low in $68.4 \%$ children with severe anaemia. A study on Malawian children had shown the incidence to be $30.4 \% .^{5}$ This high incidence in the current study could be due to absence of animal products in their diet or some genetic cause, which needs further investigation.

Folate levels were found to be low in $36.8 \%$ cases. This could be an underestimation of the condition, because folate deficiency can be masked by vitamin B12 deficiency ${ }^{18}$ and we had measured the plasma concentration of folate rather than erythrocyte concentration.

Hereditary haematological disorders especially sickle cell disease, G6PD deficiency, haemoglobinopathies and allied haemolytic disorders occur in high frequencies among different tribal groups. ${ }^{6}$ The frequency of G6PD deficiency gene in various primitive tribal population of Odisha is very high ranging from $7.7 \%$ to $15.9 \%$ in various studies. ${ }^{6}$ In the current study, we found haemoglobin disorders and G6PD deficiency in $9.5 \%$ and $5.6 \%$ of children respectively. Haemoglobinopathies and suboptimal vitamin A status were found to be more significant aetiologies in a study conducted among Northeast Thai school children. ${ }^{19}$

In the index study, a single aetiology contributing to severe anaemia could only be found in 7 (5\%) children who had iron deficiency. Rest 129 (95\%) children had multiple aetiologies leading to severe anaemia. They are depicted in Table 8. So IDA, vitamin B12 deficiency, folic acid deficiency, chronic infection or inflammation, genetic disorders like sickle cell anaemia, thalassemia and G6PD deficiency, either singly or in different combinations have contributed to severe anaemia in these children.

Some studies have shown bacteraemia, most commonly due to non-typhoid salmonella to be strongly associated with severe anaemia, justifying empirical antibiotic treatment in these children.5,20 Vitamin A deficiency is associated with malaria and bacteraemia in children with severe anaemia. ${ }^{5}$ Serum retinol levels and blood culture were not done in the present study, which could have given some more insight to the problem.

\section{CONCLUSION}

Several independent and overlapping conditions are associated with severe anaemia in tribal children. Vitamin B12 deficiency and chronic infection or inflammation are major contributors of severe anaemia besides iron deficiency. Management of severe anaemia should not be restricted to blood transfusion and iron-folic acid treatment only, but other causes of anaemia should be explored and appropriate therapeutic intervention can be done to decrease the morbidity and mortality.

\section{REFERENCES}

1. WHO. Haemoglobin concentrations for the diagnosis of anaemia and assessment of severity. Vitamin and Mineral Nutrition Information System. Geneva, World Health Organisation, 2011. (WHO/NMH/NHD/MNM/11.1) (http://www.who.int/vmnis/indicators/haemoglobin. pdf,)

2. Cook JD. Iron deficiency anaemia. Baillieres Clin Haematology 1994;7(4):787-804.

3. Anaemia among women and children. The DHS programme. (http://dhsprogram. com/pubs/pdf/OD28/ 12Chapter12.pdf,

4. Diaz JR, de las Cagigas A, Rodriguez R. Micronutrient deficiencies in developing and affluent countries. Eur J Clin Nutr 2003;57(Suppl 1):S70-2.

5. Calis JCJ, Phiri KS, Faragher EB, et al. Severe anemia in Malawian children. N Eng J Med 2008;358(9):888-89.

6. Health status of primitive tribes of Orissa. ICMR Bulletin 2003:33(10).

7. Nayak AN. Primitive tribal groups of Orissa. Orissa review (Census Special). 2010:202-5.

8. WHO. Iron deficiency anaemia. Assessment, prevention, and control. A guide for programme managers. WHO 2001; P. 114.

9. Zimmermann MB, Hurrell RF. Nutritional iron deficiency. Lancet 2007;370(9586):511-20.

10. Orkin S. Reference values in infancy and childhood. In: Orkin Stuart H. edr. Nathan and Oski's Hematology of infancy and childhood. $7^{\text {th }}$ edn. Philadelphia: Elsevier Saunders 2009.

11. Jain N, Jain VM. Prevalence of anaemia in school children. Medical Practice and Review 2012;3(1):1-4.

12. Centers for Disease Control and Prevention. Recommendations to prevent and control iron deficiency in the United States. MMWR Morb Mortal Wkly Rep 1998;47(RR-3):1-29.

13. Wharton BA. Iron deficiency in children: detection and prevention. Br J Haematol 1999;106(2):270-80.

14. Beard JL. Iron biology in immune function, muscle metabolism and neuronal functioning. J Nutr 2001;131(2S-2):568S-580S.

15. Duque X, Flores-Hernandz S, Flores-Huerta S, et al. Prevention of anaemia and deficiency of iron, folic acid, and zinc in children younger than 2 years of age who use the health services provided by the mexican social security institute. BMC Public health 2007;7:345. 


\section{Jemds.com}

16. Righetti AA, Koua AY, Adiossan LG, et al. Etiology of anaemia among infants, school aged children, and young non-pregnant women in different settings of south central cote d'lvorie. Am J Trop Med Hyg 2012;87(3):425-34.

17. Acharya U, Gau JT, Horvath W, et al. Hemolysis and hyperhomocysteinemia caused by cobalamin deficiency: three case reports and review of literature. J Hematol Oncol 2008;1:26.

18. Dierkes J, Domrose U, Ambrosch A, et al. Supplementation with vitamin B12 decreases homocysteine and methylmalonic acid but also serum folate in patients with end-stage renal disease. Metabolism 1999;48(5):631-5.

\section{Original Research Article}

19. Thurlow RA, Winichagoon $P$, Green $T$, et al. Only a small population of Anaemia in northeast Thai school children is associated with iron deficiency. Am J Clin Nutr 2005;82(2):380-7.

20. Brent AJ, Oundo JO, Mwangi I, et al. Salmonella bacteremia in Kenyan children. Pediatr Infect Dis J 2006;25(3):230-6. 